\title{
Experiência de mães de crianças com leucemia: sentimentos acerca do cuidado domiciliar
}

EXPERIENCIA DE MADRES DE NIÑOS CON LEUCEMIA:

SENTIMIENTOS ACERCADEL CUIDADO DOMICILIARIO

\author{
Jaciane Klassmann', Kátia Renata Antunes Kochia², \\ Tatiane Sano Furukawa ${ }^{3}$, leda Harumi Higarashi ${ }^{4}$, Sonia Silva Marcon ${ }^{5}$
}

\section{RESUMO}

Estudo descritivo, desenvolvido junto a seis mães de crianças com leucemia, internadas em um hospital especializado, com o objetivo de conhecer quem são as crianças atendidas no serviço e identificar como as mães percebem a experiência de cuidar no domicílio e como elas avaliam as orientações recebidas para este cuidado. Os resultados revelaram que apesar das dúvidas, dificuldades e conflitos no interior da família, as mães cuidam com desvelo e se sentem bem em poder fazer isto, e buscam na religiosidade forças para enfrentar a situação. Observou-se ainda que elas sentem necessidade de maior interação com a equipe de enfermagem e que não se sentem à vontade para expressar expectativas ou questionamentos, mesmo quando não compreendem as orientações, revelando a existência de lacunas no âmbito da função educativa-assistencial dos profissionais enfermeiros, como subsídio para atuação da mãe/cuidadora no contexto domiciliar.

\section{DESCRITORES}

Leucemia.

Saúde da criança.

Família.

Enfermagem oncológica.

\begin{abstract}
This is a descriptive study carried out with six mothers of children suffering from leukemia admitted to a specialized hospital. The objective of the study was to find out who the children being treated in this service are and to identify how mothers perceive the experience of caring for their child at home and how they evaluate the orientation they receive for this type of care. The results revealed that, in spite of doubts, difficulties and conflicts within the family, mothers care for their children with selflessness and feel positive about doing so, resorting to religion to get strength to face the situation. It was also observed that mothers feel a need for further interaction with the nursing staff, but do not feel at ease to express their expectations and questions, even at times when they do not understand the orientations. This is an indication of serious gaps regarding the nursing professional's function of providing assistance and educational support to the mother/caregiver within the family context.
\end{abstract}

\section{KEY WORDS}

Leukemia.

Child health.

Family.

Oncologic nursing.

\section{RESUMEN}

Se trata de un estudio descriptivo, desarrollado con seis madres de niños con leucemia, internadas en un hospital especializado, con el objetivo de conocer quiénes son los niños atendidos en el servicio e identificar cómo perciben las madres la experiencia de cuidar en el domicilio y cómo evalúan las orientaciones recibidas para este cuidado. Los resultados revelaron que a pesar de las dudas, dificultades y conflictos en el interior de la familia, las madres cuidan con desvelo y se sienten bien de poder hacer esto, y buscan en la religiosidad fuerzas para enfrentar la situación. Además se observó que ellas sienten necesidad de más interacción con el equipo de enfermería y que no se sienten cómodas para expresar expectativas o cuestionamientos, aun cuando no comprenden las orientaciones, revelando la existencia de lagunas en el ámbito de la función educativa-asistencial de los profesionales enfermeros, como subsidio para la actuación de la madre/cuidadora en el contexto domiciliario.

\section{DESCRIPTORES}

Leucemia.

Salud del niño.

Família.

Enfermería oncológica.

\footnotetext{
${ }^{1}$ Enfermeira. Mestre em Enfermagem. Professora do Departamento de Enfermagem da Pontifícia Universidade Católica do Paraná - Campus Toledo. Londrina, PR, Brasil. jacianeklassmann@yahoo.com.br ${ }^{2}$ Enfermeira. Mestre em Enfermagem. Professora da Universidade Tuiuti do Paraná e Instituto de Ensino Superior Pequeno Príncipe. Londrina, PR, Brasil. kanurse@hotmail.com ${ }^{3}$ Enfermeira. Mestranda em Enfermagem na Universidade Estadual de Maringá (UEM). Maringá, PR, Brasil. tatifurukawa@bol.com.br ${ }^{4}$ Enfermeira. Doutora em Educação. Professora do Departamento de Enfermagem da UEM. Maringá, PR, Brasil. inhigarashi@uem.br ${ }^{5}$ Enfermeira. Doutora em Enfermagem. Professora do Departamento de Enfermagem da UEM. Coordenadora do Mestrado em Enfermagem. Maringá, PR, Brasil. soniasilva.marcon@gmail.com
} 


\section{INTRODUÇÃO}

A despeito dos inúmeros progressos tecnológicos na área da assistência à saúde, cada vez mais parece evidenciar-se a importância de medidas básicas simples, de orientação e apoio às pessoas acometidas por enfermidades. Neste sentido, há que se reconhecer que o núcleo familiar e o domicílio, constituem em seu conjunto, o locus ideal à recuperação da saúde da pessoa portadora de uma doença crônica, especialmente em se tratando de crianças. Se o ambiente hospitalar inspira em muitas pessoas a sensação de uma ameaça real ao cotidiano de vida, possivelmente em decorrência da vinculação quase imediata às idéias de doença, sofrimento e morte; no caso das crianças, há ainda o agravante dos sentimentos de perda e separação.

Muitas conquistas têm se efetivado no sentido de mudar esta imagem acerca da experiência de hospitalização infantil. Assim, o estabelecimento do Estatuto da Criança e do Adolescente (ECA) em 1990, representou um grande avanço na busca de assegurar à criança hospitalizada, uma abordagem mais individualizada e pautada em suas necessidades específicas, na medida em que transforma a necessidade do acompanhamento hospitalar, num direito inalienável de toda criança/adolescente enfermo submetido à internação.

Não obstante tal regulamentação, e muito embora grande parte das instituições hospitalares já preconize esta medida em sua rotina de atenção, reconhecendo o papel fundamental da permanência da mãe ou de um ente familiar significativo durante a internação, a hospitalização constitui-se ainda em processo de separação doloroso para a criança: separação dos amigos, do ambiente aconchegante do lar, dos brinquedos... e uma quebra na rotina de vida de um ser incapaz de compreender de forma completa esta condição, que lhe impõe uma transformação drástica do cotidiano infantil.

No caso de uma doença crônica, a opção de conduzir o tratamento no ambiente domiciliar, junto a família, surge muitas vezes como estratégia mais adequada às necessidades específicas deste ser criança. Para tanto, caberia à equipe de saúde viabilizar um preparo adequado, ainda durante a estadia hospitalar, para que a família pudesse dar continuidade à terapêutica iniciada na internação, em seu domicílio, agregando aos procedimentos técnicos adequadamente executados, todos os benefícios inerentes ao contexto familiar em que os mesmos seriam realizados.

Entre as doenças caracterizadas pela condição de cronicidade, estão alguns tipos de câncer. A revelação de um diagnóstico como este na infância, explode de forma devastadora no seio familiar, acarretando profundas alterações em sua estrutura e organização. A doença acaba assim, afetando não só a unidade familiar, mas também, as relações desta ou de seus membros com as outras pessoas ${ }^{(1)}$.

Desta forma, é impossível discutir a problemática da criança com câncer, sem levar-se em conta que neste caso, não é apenas a criança quem adoece e precisa de cuidados, mas sim toda a sua família(2).

No caso da família da criança com câncer é possível observar que a mesma acaba por vivenciar juntamente com a criança acometida, todo o processo de enfrentamento da doença e os desafios cotidianos de cuidar de um filho outrora sadio, que, de um momento para o outro, vê-se submetido a um turbilhão de transformações físicas, fisiológicas e psicológicas ${ }^{(3)}$.

A rotina de vida da criança e de sua família é transformada por completo pelo advento de uma doença crônica como o câncer, delineando um processo de adaptação gradativa às novas situações que a doença impõe, demandando esforços em intensidade e extensão variáveis ${ }^{(3)}$.

Neste contexto, e com o objetivo de promover a saúde e, mais do que isto, a qualidade de vida destas crianças, as orientações de enfermagem são essenciais, tanto no decorrer das internações freqüentes por que passam estes pacientes, quanto no momento da alta hospitalar. As orientações de enfermagem constituem um processo educativo inerente ao ato de assistir a criança enferma e sua família. Este processo deve ser desenvolvido por meio do diálogo permanente, das demonstrações e do ensino dos cuidados básicos e específicos, promovendo o desenvolvimento de habilidades e a aquisição de conhecimentos por parte daquele que será o cuidador domiciliar. Este processo educativo-assistencial tem como meta contribuir para a construção de uma condição de maior autonomia das famílias para lidarem com o cuidado na doença crônica, permitindo-se assim, um retorno ao lar menos traumático e a continuidade da assistência de que a criança precisa.

Deste modo, o cuidador domiciliar bem orientado passa a exercer uma assistência à criança doente, respaldado em conhecimentos que permitem reduzir a ansiedade dela, executar procedimentos com maior segurança e detectar intercorrências de modo mais precoce, a fim de evitar agravos preveníveis e reinternações desnecessárias ${ }^{(4)}$.

A família assume assim, importância fundamental para o sucesso de iniciativas desta natureza. Ao enfermeiro e aos demais profissionais de saúde, por sua vez, cabe a responsabilidade e o compromisso de tornar isto possível, por meio da construção de competências para o fazer educativo em saúde. Para que iniciativas desta natureza logrem êxito, faz-se necessário que as orientações sejam passíveis de entendimento pelo cuidador e também, pelo paciente, sempre que possível. Para tanto, o 
orientador, neste caso o enfermeiro, deve ter sensibilidade para avaliar a condição cognitiva e emocional do cuidador, utilizando-se de linguagem acessível e metodologia adequada, no sentido de facilitar a compreensão destes conteúdos específicos pelo mesmo ${ }^{(5)}$.

Partimos assim, da premissa de que o cuidado deve ser entendido como uma forma de viver, de ser e de se expressar, enquanto contribuição para o bem-estar e para a promoção das potencialidades e da dignidade huma$n a^{(6)}$. Dentro desta linha de raciocínio, e reconhecendo as inúmeras possibilidades desta concepção de cuidado no campo da atuação do enfermeiro, o presente estudo buscou delinear a importância das orientações de enfermagem, a partir da perspectiva de mães cuidadoras de crianças afetadas por uma doença crônica - a leucemia, forma mais freqüente de câncer infantil.

A leucemia pode ser classificada em linfoblástica e mieloblástica, e, até 1980 constituía-se na causa mais comum de morte em crianças acometidas com câncer. Desde então, as novas técnicas de tratamento da doença vem contribuindo para reduzir progresssivamente a mortalidade por leucemia, haja visto que a sobrevida por mais de cinco anos, considerada como critério de cura da doença, tem sido de aproximadamente $80 \%$ nos últimos $\operatorname{anos}^{(7)}$.

Com base nestas considerações, este estudo teve como objetivos: a) - Delinear quem são as crianças atendidas no serviço e b) - Identificar como as mães destas crianças percebem a experiência de cuidar no domicílio e como avaliam as orientações realizadas pela equipe de enfermagem para a efetivação deste cuidado.

\section{MÉTODO}

Trata-se de um estudo descritivo, orientado pelos pressupostos do método qualiquantitativo no que concerne a seu esquema interpretativo. Os dados numéricos, neste contexto, servem para apontar tendências de opiniões, não se constituindo no aspecto central da análise. Assim, a ênfase nos aspectos qualitativos se justifica porque o objeto de conhecimento é o ser humano e este objeto que também é sujeito, recusa-se a se revelar apenas nos números $^{(8)}$.

A pesquisa foi desenvolvida junto a seis mães de criança com leucemia em tratamento no Hospital Infantil Pequeno Príncipe, sediado no município de Curitiba-Pr. Este serviço é conceituado como referência em saúde na área de leucemia, com um setor de Hematologia que realiza em média 2700 atendimentos/mês, que incluem quimioterapias, consultas e uma média de 160 internações pediátricas ao ano.

As informações foram coletadas ao longo do mês de maio de 2005, por meio de entrevista semi-estruturada, utilizando-se um gravador para o registro das falas, com posterior transcrição de todo o conteúdo. Neste processo de entrevista, além da caracterização da população, foram abordadas questões relativas à experiência de cuidado à criança com leucemia no domicílio, com foco nas dificuldades e nas orientações recebidas para subsidiar este cuidado. Foram selecionadas para o estudo mães que eram responsáveis pelo cuidado da criança no domicílio e que as acompanhavam em todas as internações.

Os discursos foram avaliados em sua singularidade e subjetividade, e os dados trabalhados por meio da análise dos discursos ${ }^{(8)}$. Assim, após leitura e escuta flutuante realizada pelos autores, os dados foram refletidos, visando a escansão e o reagrupamento em sistema de categorias e identificação de temas significativos a serem interpretados.

Para facilitar a interpretação e discussão dos dados coletados, estes foram trabalhados sob uma organização, onde traduzimos as questões do instrumento utilizado nas entrevistas em tópicos seqüências. Para fins de apresentação dos dados e discussão dos resultados, e no sentido de preservar o anonimato dos participantes, estes estão identificados por nomes de flores. Tal estratégia objetiva, de um lado, a preservação das identidades das mães entrevistadas, ao mesmo tempo em que torna possível, estabelecer aproximações e distinções entre os discursos destas participantes, ora resguardando as singularidades, ora permitindo traçar tendências coletivas, num processo de inter-relações à luz dos referenciais teóricos utilizados para este fim.

As mães, após terem sido orientadas e informadas quanto aos critérios norteadores do estudo e seus objetivos, aceitaram participar do mesmo e assinaram o Termo de Consentimento Livre e Esclarecido. A condução do estudo se deu em plena consonância com os preceitos éticos, atendendo as prerrogativas da Resolução 196/96-CNS para pesquisas envolvendo seres humanos, tendo sido o projeto aprovado pelo comitê de ética em pesquisa da instituição, em 25 de julho de 2005.

\section{RESULTADOS E DISCUSSÃO}

Os dados estão apresentados em dois momentos, no primeiro, consta uma caracterização do universo de estudo, englobando dados referentes à criança e a mãe/família, e no segundo, as categorias que emergiram dos relatos das mães sobre sua experiência de cuidado da criança no domicílio. Foi possível delinear três categorias:

1) Como a mãe percebe a experiência de cuidar da criança no domicílio,

2) Experienciando o cuidado ao filho com leucemia: principais dúvidas e dificuldades relatadas pelas mães,

3) Como a mãe percebe as orientações para o cuidado: desvelando o processo de orientação e comunicação. 


\section{Caracterização do universo de estudo: Quem são e de onde vem as crianças atendidas no serviço}

Ao buscarmos identificar quem são as crianças atendidas no serviço constatamos que a despeito da literatura apontar uma maior ocorrência da leucemia em meninos, após um ano de idade, e com incidência máxima entre dois e cinco anos de vida ${ }^{(7)}$, o número de crianças leucêmicas deste estudo era o mesmo nos dois sexos e abarcava faixa etária ampla, que se estendia dos 3 aos 13 anos de idade. Quanto ao tempo transcorrido desde o diagnóstico da doença, este variou de 4 meses até 11 anos (com uma média de cinco anos), o que se leva a deduzir que a clientela deste estudo apresentou-se bastante heterogênea em termos das fases de enfrentamento da doença em que se encontravam, bem como em termos das experiências vivenciadas com a doença e suas repercussões no seio familiar.

Um aspecto bastante relacionado com esta experiência é o número de internações pelas quais a criança já passou, sendo observado uma relação direta com o tempo de diagnóstico e também com a evolução da doença. As internações para as crianças com este tipo de diagnós- tico são muito frequentes por conta das características do próprio tratamento com a quimioterapia antineoplásica. No serviço em estudo, o protocolo de tratamento prevê um total de cinco fases: 1) quatro semanas de indução, 2) duas semanas de consolidação, 3) sete semanas de intensificação, 4) oito semanas de consolidação tardia e 5) manutenção que se prolonga até completar dois anos de tratamento. As outras causas de internação citadas foram: anemia, pneumonia, infecção e exames complementares - cada uma com uma citação.

Diante de um protocolo terapêutico tão longo como este, a procedência das crianças e as condições financeiras da família assumem papel relevante, o que nos motivou a investigar estas características. No Quadro 1 observa-se que a maioria das crianças reside em municípios localizados no mesmo Estado em que se situa o Hospital Pequeno Príncipe, porém distantes mais de $400 \mathrm{~km}$ da capital. Uma das famílias residia a mais de $2000 \mathrm{~km}$. Estas distâncias demandavam um tempo de deslocamento que variava de 6 a 32 horas, com utilização prevalente de transporte rodoviário coletivo, uma vez que só duas crianças eram transportadas por ambulância.

Quadro 1 - Características, história pregressa e procedência das crianças com leucemia - Curitiba - 2005

\begin{tabular}{|c|c|c|c|c|c|c|c|c|}
\hline Identificação & Gênero & $\begin{array}{l}\text { Idade da } \\
\text { Criança } \\
\text { em anos }\end{array}$ & $\begin{array}{c}\text { Tempo } \\
\text { da } \\
\text { doença }\end{array}$ & $\begin{array}{c}\mathrm{N}^{\circ} \text { de } \\
\text { internações }\end{array}$ & $\begin{array}{l}\text { Município de } \\
\text { Residência }\end{array}$ & $\begin{array}{l}\text { Distância } \\
\text { domicilio }\end{array}$ & $\begin{array}{c}\text { Tempo de } \\
\text { Viagem }\end{array}$ & $\begin{array}{c}\text { Meio de } \\
\text { Transporte }\end{array}$ \\
\hline Lírio & masculino & 13 & 5 anos & 14 & Colombo & $19 \mathrm{~km}$ & $20 \mathrm{~min}$ & Ônibus \\
\hline Cravo & masculino & 3 & 4 meses & 3 & Marmeleiro & $468 \mathrm{~km}$ & $6 \mathrm{~h}$ & Ambulância \\
\hline Margarida & feminino & 6 & 3 anos & 5 & Toledo & $556 \mathrm{~km}$ & $8 \mathrm{~h}$ & Ambulância \\
\hline Camélia & feminino & 11 & 11 anos & Perdeu a & Alta Floresta & $2.244 \mathrm{~km}$ & $32 \mathrm{~h}$ & Ônibus \\
\hline Jasmin & masculino & 8 & 18 meses & $\begin{array}{c}\text { contagem } \\
12\end{array}$ & Francisco Beltrão & $470 \mathrm{~km}$ & $6 \mathrm{~h}$ & Ônibus \\
\hline Crisântemo & feminino & $\begin{array}{c}\circ \\
10\end{array}$ & 9 meses & 5 & Pato Branco & $427 \mathrm{~km}$ & $6 \mathrm{~h}$ & Ônibus \\
\hline
\end{tabular}

Estes são fatores que não podem ser desconsiderados no processo de análise dos contextos de tratamento e acompanhamento dessas crianças, principalmente ao ser analisado o impacto desta e de outras dificuldades sobre a qualidade da assistência e de vida das famílias estudadas. Mesmo após a finalização das intervenções terapêuticas, o processo do cuidar deve contemplar não somente as ações de resgate da saúde do filho, mas também a preservação da integridade familiar ${ }^{(3)}$.

No caso específico das crianças leucêmicas, o distanciamento dos centros de tratamento constitui uma variável importante a ser considerada dentro do panorama terapêutico-assistencial. Uma pessoa com câncer pode apresentar-se indisposta para deixar sua residência e, a condição de saúde da criança com leucemia, sobretudo após a quimioterapia antineoplásica, constitui uma situação ainda mais difícil quando associada à distância entre sua residência e a instituição onde está sendo efetivado o tratamento. Assim, ao conjunto de preocupações dos pais com a doença, somam-se aquelas relacionadas com as viagens: a distância a ser percorrida, o desgaste físico e psicológico, além da possibilidade dos efeitos colaterais dos medicamentos antineoplásicos - náuseas, emese, diarréia, obstipação intestinal, hipotensão, mal-estar generalizado, dentre muitos outros ${ }^{(2)}$.

A oferta dos serviços de saúde no Brasil, em muitas situações, dificulta o atendimento das necessidades de saúde da população, pois as instituições de saúde que comportam o atendimento de especialidades de maior complexidade são sediadas e concentradas nos grandes centros urbanos. No caso do Hospital Pequeno Príncipe, tido como referência no tratamento de crianças com câncer, é comum o deslocamento de pessoas oriundas de localidades próximas ou distantes, em busca de um arsenal tecnológico capaz de suprir as suas necessidades terapêuticas.

A saúde assegurada na legislação brasileira deveria constituir-se como um direito de cidadania a ser garantido pelo Estado, sendo a universalidade da atenção procedente de um modelo social ético e equânime norteado pela inclusão social e solidariedade humana. Isso significa entender a saúde como um bem público, de direito individual e coletivo, permitindo que as pessoas tenham acesso facilitado aos serviços de saúde ${ }^{(9)}$, esta porém, não 
parece se constituir na realidade vivenciada pela grande maioria das famílias de crianças com leucemia em tratamento neste e em outros Hospitais, todos localizados em grandes centros.

Estudos sobre fatores associados às internações hospitalares têm revelado que as pessoas sem renda, bem como as sem escolaridade, apresentam coeficientes de internação muito maiores, quando comparadas a indivíduos pertencentes a outros grupos de melhor poder aquisitivo e maior escolaridade $^{(10)}$. Fatores como estes, portanto, contribuem para o aparecimento de infecções, que são a principal causa de morte em crianças com leucemia. Isto nos levou a querer investigar como seriam as condições de vida destas crianças expressas a partir de variáveis sócio-demográficas da mãe e de algumas características da vida em família apresentadas no Quadro 2, onde é possível perceber que a maioria das mães era casada e do lar, tinham idade entre 28 a 42 anos e baixa escolaridade (ensino fundamental incompleto). A escolarização encontrada corresponde à média da população brasileira, visto que a maioria dos brasileiros possui de quatro a sete anos de estudo, equivalente ao ensino fundamental incompleto ${ }^{(11)}$.

A renda de todas as famílias em estudo é baixa, principalmente em se considerando as demandas criadas pela situação de doença do filho. Esses dados, no entanto, são compatíveis com os da maioria das pessoas ocupadas acima de dez anos em nosso país, que tem uma renda mensal média de um a dois salários mínimos ${ }^{(11)}$. Neste sentido, observa-se que as habitações onde residem estas crianças, comportam número grande de pessoas em relação ao número de cômodos existentes. Este dado corrobora a inferência acerca do baixo poder aquisitivo das famílias, ao mesmo tempo em que delineia, em certa medida, os contextos em que se realizam os cuidados domiciliares à criança leucêmica.

Em termos das implicações destes fatores no contexto do cuidado infantil, tem-se que, da escolaridade dos familiares, sobretudo da mãe, depende a utilização mais ou menos eficiente dos serviços públicos, inclusive os de saúde, que estiverem ao alcance da família. A escolaridade materna (e a dos demais familiares da criança) exerce influência também sobre as oportunidades de emprego e de salários e, nessa medida, condiciona o próprio poder aquisitivo das famílias. Tanto a escolaridade como a profissão do cuidador parece interferir diretamente sobre a renda familiar, e indiretamente, sobre a capacidade de gestionar de forma eficiente as questões inerentes ao cuidado com a saúde.

Sabe-se que a tendência das condições de saúde na infância é fortemente condicionada pela evolução do poder aquisitivo das famílias que possuem crianças e pela progressão da escolaridade dos membros destas ${ }^{(10)}$. Do poder aquisitivo das famílias dependem, por exemplo, a disponibilidade de alimentos, a qualidade da moradia e o acesso a serviços essenciais como os de saneamento e os de assistência à saúde.

Quadro 2 - Características sócio-demográficas e econômicas das famílias das crianças com leucemia - Curitiba - 2005

\begin{tabular}{|c|c|c|c|c|c|c|c|}
\hline Sujeitos & $\begin{array}{l}\text { Idade } \\
\text { da mãe }\end{array}$ & $\begin{array}{l}\text { Escolaridade } \\
\text { da mãe }\end{array}$ & $\begin{array}{l}\text { Ocupação } \\
\text { da mãe }\end{array}$ & $\begin{array}{l}\text { Renda } \\
\text { familiar }\end{array}$ & $\begin{array}{l}\text { Tipo de } \\
\text { domicilio }\end{array}$ & $\begin{array}{l}\text { Número de pessoas } \\
\text { no domicilio }\end{array}$ & $\begin{array}{l}\text { Número de } \\
\text { cômodos }\end{array}$ \\
\hline Lírio & 21 & $6^{\mathrm{a}}$ serie & $\begin{array}{l}\text { Operadora } \\
\text { de máquina }\end{array}$ & 380,00 & alugado & 4 & 4 \\
\hline Cravo & 41 & $4^{\circ}$ série & Do lar & ignorado & financiado & 4 & 5 \\
\hline Margarida & 34 & $4^{\mathrm{a}}$ serie & Do lar & 320,00 & próprio & 7 & 4 \\
\hline Camélia & 47 & $2^{\circ}$ grau & Do lar & 740,00 & próprio & 4 & 5 \\
\hline Jasmin & 34 & $1^{\circ}$ série & Do lar & 900,00 & alugado & 4 & 5 \\
\hline Crisântemo & 42 & $4^{\circ}$ série & Doméstica & 400,00 & próprio & 4 & 6 \\
\hline
\end{tabular}

\section{Como a mãe percebe a experiência de cuidar da criança no domicilio}

Quando questionadas sobre como tem sido a experiência de cuidar da criança com leucemia no domicilio, as mães cuidadoras revelaram acima de tudo, apoio na fé e força interior:

Graças a Deus, acho que consegui cuidar (Lírio).

Eu sinto que eu tenho força. Às vezes pode faltar alguma coisa, né?! Porque o pai dele ganha muito pouquinho. Mas me sinto preparada para enfrentar tudo (Margarida).

Constatam-se nos relatos das mães, que elas se sentem dispostas e preparadas quanto ao cuidado domiciliar da criança leucêmica. O que é muito importante para o sucesso do tratamento, visto que em decorrência da complexidade desta doença, seu tratamento deve abranger todas as necessidades do doente, não somente as físicas, mas as sociais e psicológicas ${ }^{(12)}$. Nesse aspecto, a participação da família dirige-se fundamentalmente ao papel de acolhimento da criança, no sentido de buscar sua desospitalização. Para tanto, faz-se necessário que as mães, bem como os demais familiares, estejam cada vez mais preparados e aptos a cuidarem da criança doente. Esta aptidão se constrói, de um lado, pelo fato da mãe sentir-se responsável pelo cuidado com o filho e, por outro, pela segurança transmitida à mãe pelos profissionais de saúde. A mãe sente-se assim, respaldada e amparada, na medida em que se assegurem a ela os conhecimentos necessários acerca da doença e de seu tratamento, o que ocorre por meio de orientações recebidas durante todo o processo da doença, desde o diagnóstico, passando pelos períodos de internações e pela alta hospitalar. 
À despeito disto, as mães costumam se mostrar inseguras e questionar sua capacidade de lidar com o cuidado no domicílio e isto parece guardar uma relação importante com a visão que elas tem do processo de adoecer. Esta visão engloba o conjunto de crenças que os pais possuem em relação ao diagnóstico, causa, gravidade, prognóstico e curso da doença ${ }^{(13)}$.

Quando questionadas, mais especificamente, sobre como se dá este processo de cuidado no domicílio, as mães revelaram o desvelo:

Tenho muita fé que ele sare. Eu cuido dele com muito cuidado, procuro dar o remédio na hora certa. Tem que pegar com Deus que não vai ficar..., tenho muita fé em Deus que ele sare... (Lírio).

Eu me sinto uma mãe que quero cuidar e ir até o fim, que se Deus quiser eu vou lutar e vou conseguir(Camélia).

\section{A satisfação em poder cuidar}

Me sinto mais mãe do que eu já era (Jasmin).

E também os conflitos que este cuidado desencadeia no seio familiar

... minha filha fica até revoltada que eu dou proteção só para ele, mas é... no caso dele, ele é especial, eu tenho que cuidar dele, né? E ela tem que entender isso, porque é ele, eu tenho que cuidar dele (Lírio).

A única coisa que eu sinto é a hora que eu tenho que ficar no hospital, deixar os outros em casa, dá uma dó né?! Sinto muito. Eles precisam tanto de mim né, são pequenos... só isso (Margarida).

Observa-se que a falta de atenção aos outros filhos não só é cobrada por estes, como também sentida pela própria mãe. Sendo assim, os profissionais de saúde podem e devem atuar com o propósito de mostrar para estas mães que os outros filhos têm capacidade de compreender a situação, desde que devidamente esclarecidos sobre a doença e seu tratamento ${ }^{(14)}$.

A enfermidade constitui uma condição que fragiliza física e psicologicamente o ser humano, sobretudo, se o estigma associado a ela for o de uma doença incurável, percebida pela sociedade, como uma condenação à morte ${ }^{(15)}$. As neoplasias, e em especial, as leucemias na infância, recebem em muitas situações, este estigma. Os pais, diante de suas responsabilidades para com sua prole, sentem um enorme pesar quando vivenciam tal problemática.

É um sentimento grande prá gente, né? Que eu nunca esperei por isso, né? Que estamos passando, mas fazer o que, né? (Crisântemo).

Como alívio para o sofrimento ocasionado pelas enfermidades, os cuidadores buscam na religiosidade forças para enfrentar a situação e continuar cuidando.
$\mathrm{Ai}$, olha, nem sei como dar explicação. É um tipo de coisa que a gente pede que Deus, como ele deu força e coragem prá seguir até agora, ele vai continuar me dando forças prá mim, prá ter essa coragem e força e lutar com meu filho e com a ajuda de Deus, que vai ajudar ele a recuperar (Cravo).

Sendo assim, a religião ajuda o doente e o cuidador a prosseguirem no enfrentamento da doença, minimizando os sentimentos de impotência, ira, angústia e frustração. A experiência do sofrimento pode assim, modificar o sentido que se dá à vida.

\section{Experienciando o cuidado ao filho com leucemia: principais dúvidas e dificuldades relatadas pelas mães}

A literatura aponta como algumas das dificuldades enfrentadas por pais no ambiente domiciliar, fatores como: alteração no cotidiano familiar, comunicação ineficiente, alteração da auto-imagem e reação adversa da quimioterapia(4).

Algumas dúvidas e dificuldades nesse sentido também emanaram dos discursos das mães erntrevistadas, ao se referirem ao processo de assimilação de aprendizagens visando a transposição dos cuidados, do ambiente hospitalar, para dentro do seio familiar/ domiciliar:

No começo tive dificuldade de perguntar o nome da doença, como surgiu, como e por quê..., mas aí, o doutor e os enfermeiros me explicaram certinho, porque a (doença) dele veio da anemia e se transformou em leucemia. Daí não perguntei mais(Lírio).

Dúvida acho que não tenho mais, porque a gente com todos esses anos, já sabe o que tá acontecendo (Camélia).

Às vezes eu fico em dúvida a respeito de algum medicamento, né? Eu queria saber mais (Jasmin).

... dúvida ... Só agora, teve uma quimioterapia que era para fazer em uma hora e deu em meia hora. Estafaram, né? E deu uma convulsão na menina. Agora a gente tá fazendo exames para ver se é da cabeça ou se é da quimioterapia mesmo, né? (Crisântemo).

É possível observar, com base nos relatos das mães, que as dúvidas ocorreram prevalentemente em momento mais imediato ao diagnóstico da doença, sendo sanadas em sua maior parte, no decorrer do processo de tratamento. Contudo, em virtude do baixo nível de escolaridade predominante entre as mães entrevistadas, e em função do próprio grau de complexidade dos conhecimentos da área biomédica, pode-se inferir que muitas outras dúvidas deixaram de ser expressas, em virtude da falta de um arcabouço mínimo de conhecimento formal por parte das mães/cuidadoras, impedindo assim, a eclosão de questionamentos mais aprofundados acerca da doença e do tratamento. 
Como a mãe percebe as orientações para o cuidado: desvelando o processo de orientação e comunicação

Vários estudos trazem indícios de que fatores socioeconômicos interferem na capacidade de compreensão das famílias acerca das doenças, tratamentos e do cuidado com a criança, apontando inclusive associação entre a freqüência de internações hospitalares e as condições sócio-econômicas ${ }^{(16)}$. Contudo, não podemos deixar de considerar que no caso específico de câncer em crianças, o medo da doença é mais relacionado à falta de conhecimento do que da doença propriamente dita ${ }^{(4,15)}$.

Isto porque o conhecimento é algo que se processa na intersubjetividade do jogo social ${ }^{(17)}$. Nesse sentido, as condições e oportunidades socioeconômicas influenciam no desenvolvimento cognitivo das pessoas, bem como na habilidade de apreensão de novos conhecimentos. No contexto em questão, tal apreensão se dá na medida da compreensão das orientações realizadas durante a hospitalização e no momento da alta hospitalar. Mas para isto, os profissionais de saúde precisam desenvolver competência cultural para ouvir as narrativas dos clientes, lembrando que a narração de um fato pode modificar a maneira de encará-lo e agir sobre a situação(5).

Indubitavelmente, esta é uma variável prevalente na maior parte das realidades assistenciais investigadas, fazendo pano de fundo para o presente estudo, como foi possível verificar pelos dados anteriormente apresentados. Assim, acerca desta capacidade ou limitação compreensiva, socialmente delineada, pode-se destacar as seguintes considerações por parte das mães:

Tem umas (orientações) que não, porque eu sou meio difícil de entender, mas as outras sim. Quando voltou, sabe... a doença dela voltou, né? Agora já é a volta, não o começo. Eu pensava que não ia voltar. Os médicos não falam muito bem com a gente, sabe? Falam bem rápido, né? Alguma coisa... só. Eu sou vergonhosa de perguntar. A enfermagem é muito boa, o que elas podem fazer, né?...Tudo que o médico deixa escrito, elas falam. Dá muita atenção, elas são muito boa, muito boa (Margarida).

Geralmente é sobre a medicação mesmo (que eu não entendo) (Jasmin).

Por meio desses achados, foi possível identificar que duas mães (um terço das entrevistadas) referem dúvidas quanto às orientações fornecidas pela equipe de saúde do hospital, em especial, nas situações relacionadas à doença, ao cuidado e ao tratamento.

Vale ressaltar o fato de uma mãe referir constrangimento perante os profissionais de saúde. Tal situação constitui-se em reflexo da relação de poder e hierarquia, já tão arraigada em nossa sociedade. De forma geral, esta se manifesta no ambiente hospitalar, acrescida de um novo componente, relacionado à detenção de um conhecimento biomédico e científico por parte da equipe de saúde, e que dificilmente é bem partilhada com o doente e sua família, gerando desta forma, a verticalização nas relações entre profissional e cliente.

Outro fator que contribui para este distanciamento diz respeito à linguagem utilizada pelos profissionais para efetuar as orientações. Há que se lembrar que: o contexto lingüístico transcende a palavra... sendo assim, o sentido da fala somente é mensurado pela mudança produzida no comportamento de outrem ${ }^{(17)}$. A fala objetiva a transmissão de uma mensagem que conduz a um efeito de sentido como resultado, procedente do emissor para o destinatário. Para tanto, as orientações somente serão eficazes se o emissor considerar o contexto da fala, a subjetividade do ouvinte e permitir a abertura de um diálogo recíproco ${ }^{(17)}$.

É importante que se atente para o efetivo diálogo entre o cliente e o profissional, de tal modo que se estabeleça, por meio da reciprocidade, a confiança nas orientações transmitidas ao cuidador. Tais orientações constituem peças essenciais para a qualidade do cuidado prestado no domicilio. A valorização destes aspectos dentro do cotidiano assistencial, bem como suas repercussões, ficam evidenciadas nos relatos a seguir:

Contribuem muito. A linguagem era adequada (Lírio).

Quando eu vim... Nossa!...Não tem explicação, né? Quando eu recebi a notícia que ele tinha leucemia, a gente fica sem chão prá pisar. Com as orientações, a gente vai... né?... se habituando, entendendo, procurando entender ... (Cravo).

A enfermagem não me falou nada, só os médicos. O médico fala o que não pode comer, que não pode cair no começo... Nos primeiros internamentos, quando fomos para casa, a doutora falou que tem que cuidar para ela não cair, senão dá sangramento. Só isso!... (Margarida).

Foi possível observar, de forma geral, que as próprias mães/cuidadoras usualmente não se encontram em estado de prontidão para a aprendizagem. Isto é influenciado, em grande medida, pelo estado de choque e o nível de ansiedade destes pais em face do diagnóstico de leucemia. Assim, qualquer trabalho de cunho educativo-assistencial, para lograr sucesso, necessita obrigatoriamente ser realizado de forma continuada, e não em caráter pontual. Isto deve ser especialmente observado quando se considera que as famílias apresentam comportamentos distintos no início do tratamento e no transcorrer dele, o que modifica também suas necessidades ${ }^{(18)}$.

Além disto, foi possível notar uma baixa participação dos profissionais de enfermagem na atividade de orientação dessa clientela, sendo a mesma restrita a aspectos meramente técnico-operacionais. Cabe ressaltar que a atividade de orientação, conforme prevê o código deontológico de enfermagem, constitui um procedimento da profissão, bem como etapa do processo de atenção ao cliente.

As orientações de enfermagem acontecem, principalmente, pela comunicação estabelecida entre o profissio- 
nal de saúde e o cliente. Tal comunicação deve responder às indagações e atender as expectativas do cuidador, no caso, da mãe. Para que haja o alcance destes objetivos, é necessário o estabelecimento de um relacionamento terapêutico e de um planejamento da assistência que transcenda os aspectos tecnológicos da terapêutica. Neste sentido, um dos objetivos de atuação do profissional é o estabelecimento de um elo entre o orientador e o orientado, de tal modo que ambos consigam se interrelacionar.

As relações interpessoais na área da saúde se encontram centradas principalmente na instituição, transferindo para o paciente as normas e rotinas desta, com prevalência de atitudes e comportamentos autoritários ${ }^{(19)}$. No que se refere às relações interpessoais, os usuários dos serviços de saúde consideram as atitudes de compreensão, acolhimento e comunicação dos profissionais como instrumentos que auxiliam na solução dos seus problemas de saúde, sendo tais atitudes procedentes da efetividade das relações interpessoais ${ }^{(20)}$. Dentre as características das relações interpessoais estão o humanismo, a sensibilidade e a receptividade - que devem, em conjunto, compor o perfil dos profissionais de saúde ${ }^{(20)}$.

Ainda no aspecto da comunicação ou orientação, quando questionadas acerca da necessidade de algum outro profissional da saúde para fornecimento de suporte técnico e orientações relacionadas com o cuidado, as mães relataram:

Seria uma psicóloga, né? Mas como eu estou na casa da associação, lá isso existe também. Então ela ajuda também. Sempre que eu posso conversar com ela... que eu me sinto meio desamparada, alguma dúvida eu converso com ela e ela me dá assistência (Cravo).

Gostaria que tivesse uma nutricionista, para saber o que ele pode e o que não pode comer (Jasmin).

Tais depoimentos ratificam a idéia da importância das equipes multiprofissionais, que possibilitam um atendimento ampliado e especializado, que somam recursos de diferentes profissionais e saberes complementares para aumentar a produtividade e a racionalidade dos serviços.

Com relação às orientações de incumbência da equipe de enfermagem e aquelas realmente recebidas ou efetuadas, os cuidadores revelaram várias lacunas que concorreram no comprometimento da consolidação do cuidado ao filho leucêmico:

... igual, ele está bem debilitado. Depois da quimioterapia, queria saber se ele poderia comer qualquer coisa que ele gosta (Lírio).

... ai, tem tantas coisas que eu sei que devia fazer... Eu faço o que eu posso, né? Mas como eu sou ...bem, minha casa fica assim... lugar meio difícil, né? Tem muitas coisas que eu queria fazer, mas eu não perguntaria nada para elas (enfermeiras), porque tem bastante coisa que eu queria fazer melhor para ela (Margarida).
Sei lá, às vezes tem um tal remédio prá descer em meia hora, e desce em uma hora...Ou, às vezes, para vinte e quatro horas. E acaba ultrapassando muito as vinte e quatro horas.É difícil entender... (Jasmin).

Foi possível observar que metade das mães entrevistadas sentiu necessidade de maior interação com a equipe de enfermagem. E mais que isto, o que chama a atenção é a ausência de referência à atuação da equipe de enfermagem e ainda, o fato de que quando esta era lembrada, isto esteve relacionado a um evento de descuidado-um medicamento que deveria ter corrido em determinado tempo e que correu na metade do mesmo, e que foi agravado pelo fato da criança começar a apresentar convulsões. É importante ressaltar que, para estas mães, seus filhos encontram-se no limiar entre a vida e a morte, fato este que evidentemente exacerba e consciência que as mesmas têm acerca da importância de um tratamento correto, uma vez que qualquer descuido pode comprometer sua saúde

De forma geral, em outras situações, foram apontados indícios que corroboram para a idéia de que essas mães não se sentiram à vontade para expressar suas expectativas ou questionamentos, devido ao distanciamento entre as mesmas e os profissionais de saúde que prestam atendimento a seus filhos.

É preciso ter sempre em mente que as relações interpessoais estabelecidas pela capacidade de comunicação do profissional, são instrumentos poderosos no processo assistencial em saúde. A equipe de saúde não deve centrar suas atividades apenas em procedimentos técnicos, mas buscar o envolvimento com o cliente, numa relação mais próxima com as pessoas que precisam ou buscam ajuda(5).

Com relação as estes aspectos, não se pode deixar de considerar que os próprios profissionais de saúde e, de forma particular, os membros da equipe de enfermagem, por sua convivência diuturna e seu envolvimento com a criança, experienciam algumas dificuldades ao ter que enfrentar a situação de cuidado a uma criança com câncer. Isto interfere em sua prática e em sua relação com a família das crianças, desvelando sua fragilidade para lidar com esta questão(21).

Assim, considerando que o relacionamento humano nos serviços de saúde constitui elemento essencial para melhorar a assistência, os profissionais de saúde devem possuir habilidades interpessoais que possam nortear seu agir, de tal modo a atender, orientar, personalizar e responder às necessidades de saúde do cliente, o qual por sua vez, tem a necessidade de envolver-se, explorar, compreender e agir em todo o processo terapêutico. Sendo assim, esse processo de interação entre profissional e cliente dá-se por eficaz quando o ajudado se torna seu próprio ajudador, quando o ser humano profissional e o ser humano cliente/usuário forem, ambos, fortalecidos como agentes que percebem e elaboram símbolos e signi- 
ficados, comunicam, negociam e inter(agem) perspectivas educacionais para mudar a si e às suas realidades, diante das demandas e dos enfrentamentos necessários ao complexo processo de educar em saúde ${ }^{(5)}$.

\section{CONSIDERAÇÕES FINAIS}

Pode-se concluir que são muitas as dificuldades experimentadas pela mãe cuidadora e sua família no processo de adaptação a esta nova realidade que é o conviver e cuidar de um filho com leucemia. Tais dificuldades incluem não só o processo de aceitação gradativa desta nova realidade, quanto os problemas operacionais geradas por esta situação. Assim, somada à ambigüidade de sentimentos e reações experimentadas pela mãe ao cuidar: ora forte, batalhadora e renovada por sua religiosidade, ora culpada, triste e impotente frente a uma condição tão adversa - existe a atuação do profissional enfermeiro, que pode influenciar de forma positiva ou negativa esta balança do assistir a criança com leucemia. Assim, este estudo representa um passo ainda inicial no sentido de melhor compreender esta realidade assistencial, de modo a buscar subsídios nos próprios sujeitos que vivenciam os problemas deste enfrentamento tão duro, e a partir desta visão particular, construir possibilidades de intervenção mais efetivas junto a esta clientela.

A relação entre mãe e filho é fundamental para a boa formação psicológica do futuro adulto. Neste sentido, compreende-se que a prole sinta-se mais segura, amada e amparada na presença da mãe, podendo ter minimizadas as angústias decorrentes da hospitalização. Isto porque a mãe é a principal provedora do acolhimento da criança, sendo capaz de transmitir maior confiança e alívio em relação a atenção às necessidades físicas e afetivas da mesma.

A hospitalização e, sobretudo, um diagnóstico como o do câncer infantil agridem a criança e a família em vários aspectos que transcendem o físico, o que torna o apoio adequado a este binômio, de fundamental importância. As orientações representam um dos sustentáculos deste apoio, uma vez que tais esclarecimentos podem repercutir positivamente para a redução do medo, angústia e ansiedade que acompanham o processo de cuidado no domicílio ${ }^{(12)}$.

Por meio deste processo de investigação da realidade, observou-se que as orientações de enfermagem poderiam ser capazes de auxiliar significativamente as famílias destas crianças. Contudo, este estudo demonstrou que, para algumas mães, tais orientações não existiram; para outras, foram insuficientes do ponto de vista qualiquantitivo (restritas aos aspectos técnicos), e noutros casos, não foram dignas de nota.

No entanto, para alcançar de modo mais pleno o objetivo de apoiar e repercutir positivamente no cuidado que será proporcionado no domicílio, estas orientações devem ser mediadas por uma comunicação interpessoal re- almente efetiva, por meio da troca de mensagens verbais e não-verbais codificáveis entre os envolvidos, e marcadas por uma postura sincera e flexível, com informações coerentes às necessidades e potenciais individuais de cada mãe, e adaptada aos contextos onde tais ações terão lugar.

Este procedimento constitui o arcabouço para o estabelecimento da relação de ajuda, definida como uma relação na qual pelo menos uma das partes procura promover na outra o crescimento, o desenvolvimento, a maturidade, o melhor funcionamento e a maior capacidade de enfrentar as dificuldades da vida. Neste sentido, as orientações de enfermagem, aliadas ao trabalho interdisciplinar com os demais membros da equipe, são essenciais para promover a qualidade de saúde da criança.

A atenção educativo-assistencial ao binômio mãe e filho com leucemia, enfatizando o processo de comunicação/orientação em e para a saúde, deve favorecer a redução da angústia da criança e de sua mãe, e ao mesmo tempo consolidar um suporte técnico e emocional para o enfrentamento do processo de doença, internação e alta hospitalar, por meio da transposição deste cuidar, do hospital para o domicílio, de forma planejada e bem orientada.

O estudo possibilitou evidenciar outros entraves para a assistência integral à criança leucêmica por sua mãe e, neste aspecto, é certo que as desigualdades sociais influenciam no consumo dos serviços de saúde, sendo as classes sociais de menor poder aquisitivo as que mais se ressentem da precariedade desta assistência.

Observa-se no cenário nacional, que os acessos ainda se mostram eminentemente seletivos, excludentes e focalizados, no que se refere à localização dos serviços especializados, o que revela, um descompasso entre a legislação e a legitimidade social do direito à saúde. Para minimizar o impacto destes contextos desfavoráveis, o interesse dos profissionais e instituições é imprescindível, detectar e procurar meios que possibilitem o acesso facilitado, diagnosticar suas realidades assistenciais de modo crítico e construtivo, e acionar os demais setores para a discussão de possibilidades de intervenção efetiva.

Além da exclusão, é importante considerar que os serviços de saúde devam primar pela qualidade da atenção, o que implica atender as necessidades físicas, psicológicas e sociais dos clientes. Portanto, neste caso específico, as atividades dos profissionais não se restringem à terapêutica aplicada para a leucemia, às explicações meramente técnicas e superficiais, mas devem abarcar o estabelecimento de uma maior proximidade entre os profissionais da saúde e seus clientes. Da mesma forma, os resultados desta investigação levam a crer que a atuação do profissional de saúde também não pode ser tolhida pela impessoalidade ou pelos limites do espaço hospitalar, mas deve primar pelo conhecimento dos contextos em que as ações de saúde ocorrem: nos domicílios, nas unidades básicas e nos redutos mais longínquos e diversificados possíveis. 
Somente por meio de uma atuação mais crítica, e que resgate a reflexão acerca de novas possibilidades de fazer e pensar a assistência como uma atividade mais am- pla e impactante, será possível reconstruir um exercício profissional realmente pleno e humanizado na área da saúde.

\section{REFERÊNCIAS}

1. Delella LA, Araújo TCCF. Câncer na infância: uma investigação sobre a avaliação da desordem de estresse póstraumático parental e a experiência da sobrevivência. Psicol Argum. 2002;20(31):43-8.

2. Nascimento LC, Rocha SMM, Hayes VH, Lima RAG. Crianças com câncer e suas famílias. Rev Esc Enferm USP. 2005;39(4):469-74.

3. Ortiz MCA, Lima RAG. Experiences of families with children and adolescents after completing a cancer treatment: support for the nursing care. Rev Lat Am Enferm. 2007;15(3):411-7.

4. Misko MD, Bousso RS. Managing cancer and its intercurrences: the family deciding to seek Emergency care for the child. Rev Lat Am Enferm. 2007;15(1):48-54.

5. Boehs AE, Monticelli M, Wosny AM, Heidemann IBS, Grisotti M. A interface necessária entre enfermagem, educação em saúde e o conceito de cultura. Texto Contexto Enferm. 2007;16(2):307-14.

6. Waldow VR. O cuidado na saúde: as relações entre o eu, o outro e o cosmos. Petrópolis: Vozes; 2004.

7. Brasil. Ministério da Saúde. Instituto Nacional do Câncer (INCA). Epidemiologia dos tumores da criança e do adolescente [texto na Internet]. Brasília; (C1996-2008 [citado 2003 ago. 05]. Disponível em: http://www.inca.gov.br/ conteudo_view.asp?id=349

8. Minayo MCS. O desafio do conhecimento: pesquisa qualitativa em saúde. São Paulo: Hucitec; 2000.

9. Assis MMA, Villa TCS, Nascimento MAA. Acesso aos serviços de saúde: uma possibilidade a ser construída na prática. Ciênc Saúde Coletiva. 2003;8(3):815-23.

10. Castro MSM, Travassos C, Carvalho MS. Fatores associados às internações hospitalares no Brasil. Ciênc Saúde Coletiva. 2002;7(4):795-811.

11. Instituto Brasileiro de Geografia e Pesquisa (IBGE). Indicadores sociais mínimos [texto na Internet]. Brasília; 2003 [citado 2006 jun. 2]. Disponível em: http:// www.ibge.gov.br/home/estatistica/populacao/condicaodevida/indicadoresminimos/default_minimos. shtm

12. Almeida MI, Molina RCM, Vieira TM, Higarashi IH, Marcon SS. O ser mãe de criança dependente: realizando cuidados complexos. Esc Anna Nery Rev Enferm. 2006;10(1):36-46.

13. Knafl KA, Deatrick JA. Further refinement of the family management style framework. J Fam Nurs. 2003;9(3): 232-56.

14. Cavicchioli AC, Nascimento LC, Lima RAG. O câncer infantil na perspectiva dos irmãos das crianças doentes: revisão bibliográfica. Rev Bras Enferm. 2004;57(2):223-7

15. Yin LK, Twinn S. The effect of childhood cancer on Hong Kong Chinese families at different stages of the disease. Cancer Nurs. 2004; 27(1):17-24.

16. Caetano JRM, Bordin IAS, Puccini RF, Peres CA. Fatores associados à internação hospitalar de crianças menores de cinco anos, São Paulo-SP. Rev Saúde Pública. 2002;36(3):285-91.

17. Caravantes F. Família, subjetividade e linguagem: gramáticas da criança "anormal". Ciênc Saúde Coletiva. 2001;6(1):125-37.

18. Holm KE, Patterson JM, Gurney JG. Parental involvement and family-centered care in the diagnostic and treatment phases of childhood cancer: results from a qualitative study. J Pediatr Oncol Nurs. 2003;20(6): 301-13.

19. Monticelli M, Boehs AE. A família na unidade de internação hospitalar: entre o informal e o instituído. Rev Esc Enferm USP. 2007;41(3):468-77.

20. Samico I, Hartz ZMA, Felisberto E, Carvalho EF. Atenção à saúde da criança: uma análise do grau de implantação e da satisfação de profissionais e usuários em dois municípios do estado de Pernambuco, Brasil. Rev Bras Saúde Matern Infant. 2005;2(5):229-40.

21. Melo LDL, Valle ERM. Equipe de enfermagem: experiências do cuidar de criança com câncer nos plantões noturnos. Rev Esc Enferm USP 1998;32(4):325-34. 